\title{
PEMILIHAN MATERI/ASPEK KEBAHASAAN DALAM KURIKULUM 2013 PADA JENJANG PENDIDIKAN MENENGAH (SMP/MSN, SMA/MA, SMK)
}

\author{
I N. Martha \\ Jurusan Pendidikan Bahasa dan Sastra Indonesia, Fakultas Bahasa dan Seni \\ Universitas Pendidikan Ganesha, Singaraja, Bali, Indonesia \\ Email: nengahmartha@yahoo.com
}

\begin{abstract}
Currently, the curriculum used in secondary level of education (SMP/MSn, SMA/MA, SMK) is Kurikulum 2013. For Indonesian Language instruction, this curriculum emphasizes several things. Those are competence-based content and learning objective, process of learning and teaching based scientific models, achievement of learning and teaching based on authentic assessment, coridor of learning and teaching based on text, and product-based learning achievement. The above emphases will bring impact toward the instructional behaviour of teachers in teaching Indonesian Language at school in regard to materials/contents, process, assessment, channel, and product of learning. This article will reveal about selection of material /language aspect on Kutrikulum 2013 at secondary education level (SMP/MSn, SMA/MA, SMK).
\end{abstract}

Keywords. language aspect, Kurikulum 2013, secondary education

\begin{abstract}
ABSTRAK
Saat ini, kurikulum yang digunakan pada jenjang pendidikan menengah (SMP/MSn, SMA/MA, SMK) adalah Kurikulum 2013. Untuk pembelajaran bahasa Indonesia, Kurikulum 2013 ini menekankan beberapa hal, seperti: isi dan tujuan pembelajaran berbasis kompetensi, proses pembelajaran berbasis saintifik, tagihan pembelajaran berbasis asesmen autentik, pintu masuk pembelajaran berbasis teks, dan hasil belajar akhir berupa produk. Penekanan-penekanan yang disebut di atas akan membawa pengaruh terhadap perilaku guru dalam pembelajaran bahasa Indonesia di sekolah terkait materi/isi, proses, asesmen, jalur, dan produk belajar. Artikel ini, secara khusus akan mengungkap mengenai Pilihan Materi/ Aspek Kebahasaan dalam Kurikulum 2013 pada Jenjang Pendidikan SMP/MSn, SMA/MA, SMK.
\end{abstract}

Kata kunci: Aspek Kebahasaan, Kurikulum 2013, Pendidikan Menengah

\section{PENDAHULUAN}

Kurikulum yang digunakan pada jenjang pendidikan menengah (SMP/MSn,SMA/ MA, SMK) saat ini adalah Kurikulum 2013. Hal ini ditegaskan dalam Permendikbud No. 160, Th. 2013 tentang "Pemberlakuan Kurikulum 2013", dan disusul dengan dikeluarkannya SK No. 253/KEP.D/KR/2017 dari Dirjen Pendidikan Dasar dan Menengah Kemendikbud tentang "Penetapan Satuan Pendidikan Pelaksana Kurikulum 2013”.
Bila dicermati pada dokumen-dokumen Kurikulum 2013, kita bisa menyimak karakteristik Kurikulum 2013 terkait dengan 4 perubahan yang dilakukan, yakni perubahan pada: 1. standar kompetensi, 2. standar isi, 3. standar proses, dan 4. standar evaluasi (Kemendikbud, 2013). Perubahan pada isi tampak pada, bahwa pembelajaran dilakukan dengan mempertanyakan terlebih dahulu kemampuan apa yang kita inginkan jika kita membelajarkan mata pelajaran tertentu. Jadi harus jelas SKLnya terlebih dahulu, baru kemudian dibuatkan 
rincian kemampuan-kemampuan berikutnya dalam KI, KD. Selanjutnya kemampuankemampuan yang lebih spesifik yang mau disasar/diinginkan dirumuskan oleh guru dalam bentuk indikator yang dilengkapi dengan descriptor agar guru lebih mudah mengukurnya. Jadi indikator (kata benda) itu adalah yang mengindikasikan bila siswa dikatakan menguasai kemampuan/kompetensi tetentu ditunjukkan/diindikasikan oleh karena dia bisa atau mampu mengapa? Yang mengindikasikan itu harus yang betul-betul esensial, artinya jika kemampuan itu tidak dikuasai jangan percaya bahwa siswa kompeten/ mahir dalam hal tersebut.

Artikel ini membatasi diri pada pengungkapan standar isi yang terkait dengan pilihan aspek kebahasaan, dan yang bersifat vertikal. Tujuannya adalah untuk melihat aspek kebahasaan yang dipilih terkait dengan struktur teks yang dibelajarkan.

\section{Elemen Perubahan}

Meskipun kurikulum sebelumnya (KBK 2004, KTSP 2006) telah berbasis kompetensi, Kurikulum2013 yang juga berbasis kompetensi dengan tegas menyatakan bahwa pada Kurikulum 2013 terdapat perubahan-perubahan yang mendasar. Sedikitnya terdapat 4 perubahan dalam Kurikulum 2013. Perubahan-perubahan tersebut perlu dipahami karena nanti akan berkait dengan pemilihan materi/ aspek kebahasaan yang akan dibelajarkan.

\section{Empat Perubahan Standar dalam Kuri- kulum 2013}

Dalam Kurikulum 2013 dinyatakan terdapat empat elemen perubahan, yakni perubahan pada: standar kompetensi, standar isi, standar proses, dan standar evaluasi.

\section{a. Standar Kompetensi}

Sebagaimana disebutkan dalam Kurikulum 2013, khusunya dalam dokumen Elemen Perubahan (Kurikulum 2013), bahasa Indonesia diposisikan sebagai penghela mata pelajaran lain. Artinya, bahasa Indonesia digunakan sebagai penggotong, pembawa (carrier) ilmu pengetahuan. Jadi bahasa Indonesia dijadikan sebagai sarana/wahana komunikasi berbagai bidang yang diungkapkan dengan bahasa Indonesia.

Kompetensi yang semula diturunkan dari mata pelajaran berubah menjadi mata pelajaran dikembangkan dari kompetensi (Kurikulum 2013). Dari sini kita tahu bahwa, jika kita membelajarkan bahasa Indonesia, pertanyaan awal yang harus dijawab adalah "kemampuan apa yang kita inginkan kepada peserta didik jika kita membelajarkan bahasa Indonesia?" Jika pertanyaan itu dikaitkan dengan jenjang sekolah, maka kompetensi ini disebut SKL (mata pelajaran). Hal seperti ini tentu berbeda dengan kurikulum yang berbasis pokok bahasan, yang menonjolkan pokok bahasan terlebih dahulu dibandingkan dengan kompetensi yang bakal dibentuk.

SKL ini akan dicicil pencapaiannya dengan cara menjabarkannya menjadi KI, KD, dan indikator. Pada Kurikulum 2013, KI dan $\mathrm{KD}$ telah disiapkan secara terpusat, dan perencanaan pembelajarannya kemudian disusun dalam bentuk silabus. Sementara itu, indikator disusun oleh guru berdasarkan KI dan KD. Indikator menjadi dasar tuntutan operasional dalam pembelajaran dan evaluasinya.

Pembelajaran bahasa Indonesia bahkan pembelajaran tiap mata pelajaran mendukung semua kompetensi (sikap, keterampilan, pengetahuan) pada semua jenjang pendidikan (dasar dan menengah) karena Kurikulum 2013 menggunakan pengembangan pembelajaran dengan prinsip horizontal (dalam domain Bloom), dan dengan prinsip vertikal (makin tinggi kelas/jenjang pendidikan makin sulit, makin kompleks, makin abstrak, makin meluas, makin mendalam yang akan dibelajarkan (Kemendikbud. 2013. Elemen Perubahan Kurikulum 2013).

\section{b. Standar Isi}

Mata pelajaran sebagai isi (dalam standar isi, Kurikulum 2013) dikembangkan dari kompetensi. Dalam pengembangan isi selanjutnya, pengembangan isi dari kompetensi dipisah-pisahkan atas jenjang dan jenis pendidikannya.

Untuk SD, kompetensi dikembangkan 
menjadi: tematik terpadu dalam semua mata pelajaran

Untuk SMP, kompetensi dikembangkan menjadi:mata pelajaran

Untuk SMA, kompetensi dikembangkan menjadi: mata pelajaran

Untuk SMK, kompetensi dikembangkan menjadi: vokasional

Beberapa hal penting yang perlu mendapat perhatian terkait dengan pembelajaran bahasa sebagai isi dalam standar isi, antara lain:

1. Materi yang diajarkan ditekankan pada kompetensi berbahasa sebagai alat komunikasi untuk menyampaikan gagasan dan pengetahuan.

2. Siswa dibiasakan membaca dan memahami makna teks serta meringkas dan menyajikan ulang dengan bahasa sendiri.

3. Siswa dibiasakan menyusun teks yang sistematis, logis, dan efektif melalui latihan-latihan penyusunan teks.

4. Siswa dikenalkan dengan aturan-aturan teks yang sesuai sehingga tidak rancu dalam proses penyusunan teks (sesuai dengan situasi dan kondisi: siapa, apa, di mana).

5. Siswa dibiasakan untuk dapat mengekspresikan dirinya dan pengetahuannya dengan bahasa yang meyakinkan secara spontan.

6. Mata pelajaran dirancang terkait satu dengan yang lain dan memiliki kompetensi dasar yang diikat oleh kompetensi inti tiap kelas.

7. Bahasa Indonesia sebagai penghela mapel lain [sikap dan keterampilan berbahasa\} .

8. Bermacam jenis konten pembelajaran diajarkan terkait dan terpadu satu sama lain (cross curriculum atau integrated curriculum).

9. Konten ilmu pengetahuan diintegrasikan dan dijadikan penggerak konten pembelajaran lainnya (Kemendikbud. 2013. Standar Isi Kurikulum 2013).

\section{c. Standar Proses}

Proses pembelajaran memberi penekanan pada pengembangan kreativitas (Kurikulum 2013). Kreativitas dalam belajar dapat didukung oleh model-model pembelajaran saintifik, seperti: inquiry based learning, problem based learning, project based learning dan sejumlah model yang lain (discovery based learning, cooperative based learnig, colaborative based learning, group investigation based learning) yang mempunyai ciri langkah pembejaran: observing (mengamati) - questioning (menanya) - associating (menalar)- experimenting (mencoba) - networking (membentuk jejaring). Dengan model-model pembelajaran ini, belajar bahasa seperti belajar menemukan ilmu. Tentu hal ini menimbulkan protes atau keberatan bagi yang mengajarkan bahasa karena bahasa pada hakikatnya sebagian keterampilan (4 keterampilan berbahasa), dan sebagian ilmu (ilmu bahasa: ada kaidah fonologi, morfologi, sintaksis, dan kaidah wacana).

Meskipun keterampilan berbahasa dapat dimunculkan dalam menyimak, membaca teks dan dalam kegiatan networking hasil belajar, namun tetap direkomendasikan pula model pembelajarn lain, seperti Pedagogi Genre (dengan 4 M-nya: (membangun konteks, menelaah model, mengonstruksi terbimbing, mengontruksi mandiri) dan CLIL (Content and Language Integrated Learning) dengan 4 K-nya (konten, komunikasi, kognisi, dan kultur) untuk meningkatkan kompetensi siswa dalam menggunakan bahasa untuk tujuan komunikasi (Kemendikbud, 2017; Martha, 2005).

\section{d. Standar Penilaian}

Kurikulum 2013 menyaratkan penilaian autentik (authentic assessment) dalam mengungkap hasil belajar siswa. Tujuannya adalah agar kemampuan atau kompetensi siswa dapat diungkap sebenar-benarnya. Karena itulah instrumen pengungkapan yang digunakan tidak selalu dalam bentuk tes saja, tetapi juga dalam bentuk nontes, lebih-lebih jika kemampuan yang diungkap itu dalam bentuk unjuk kerja/unjuk laku (performance). Ini sesuai dengan makna istilah penilaian (assessment) yakni mengumpulkan semua informasi yang relevan untuk mengambil keputusan (judgement).

Dalam istilah penilaian autentik terkandung pengertian: 
1. mengukur kemampuan yang hendak diukur,

2. cara mengukurnya seperti bagaimana nanti kemampuan itu ditampilkan atau digunakan dalam dunia kerja yang sebenarnya/nyata,

3. pengukuran kemampuan itu komulatif, artinya tidak sekali saja (snapshot),

4. pengukuran kemampuan itu tidak hanya dalam hasil akhir saja, tetapi juga dalam proses agar hasil akhir tidak terlanjur menjadi bad product,

5. hasil akhir kemampuan itu merupakan gambaran konstan dari siswa itu sendiri, atau merupakan kemampuan dasarnya ( $b a-$ sic competence) siswa, artinya memang itulah kemampuan siswa yang sesungguhnya, tidak kurang tidak lebih (Sandras JR, 1989).

Di pihak lain, penerapan penilaian autentik dalam pendidikan dapat mempercepat pemanfaatan SDM karena bisa meniadakan pelatihan-pelatihan khusus lagi (training) menjelang mereka memasuki dunia kerjanya. Oleh karena itu, hal ini akan dapat mempercepat produktivitas.

Asesmen autentik termasuk: kinerja/ penampilan, esai, penilaian diri (self-assessment), proyek (investigasi yang mendalam), portofolio. Portofolio mengandung 3 hal yang penting, yakni: hasil karya siswa, penilaian diri, kriteria, dan standar penilaian. Penilaian diri ini sangat penting karena bertujuan untuk mengembangkan keterampilan melakukan refleksi, evaluasi, dan revisi terhadap proses dan produk belajarnya secara mandiri. Dalam merekam penilaian berbasis kinerja, penilai dapat menggunakan: ceklis, rekaman naratif, perekaman memori, kriteria, rubrik, dan skala penilaian (rating scale). Demikianpun untuk melakukan penilaian, penilai wajib menggunakan PAP bukan PAN karena di dalam kurikulum yang berbasis kompetensi, kekurangan penguasaan kompetensi tidak dapat ditoleransi, atau dengan kata lain harus digunakan penilaian standar (Martha, 2005).

\section{Pembelajaran Berbasis Teks}

Komunikasi dilakukan secara whole language, artinya bila kita berkomunikasi sesungguhkan kita menggunakan wacana.
Wacana itu akan mengait bentuk, makna, keterampilan berbahasa, unsur bahasa, konteks, situasi, unsur mekanik (whole language). Jadi komunikasi yang kita lakukan bukan kata per kata atau kalimat per kalimat. Wacana dapat berwujud teks tulis, lisan, atau visual. Jadi, jika kita menggunakan teks sebagai pintu masuk pembelajaran bahasa, maka sesungguhnya kita kembali pada hakikat pemakaian bahasa, yakni untuk berkomunikasi itulah bahasa itu kita pelajari (Martha, 2015).

Anatomi teks yang menggambar wacana yang whole language itu dapat kita lihat di bawah ini (Martha, 2015).

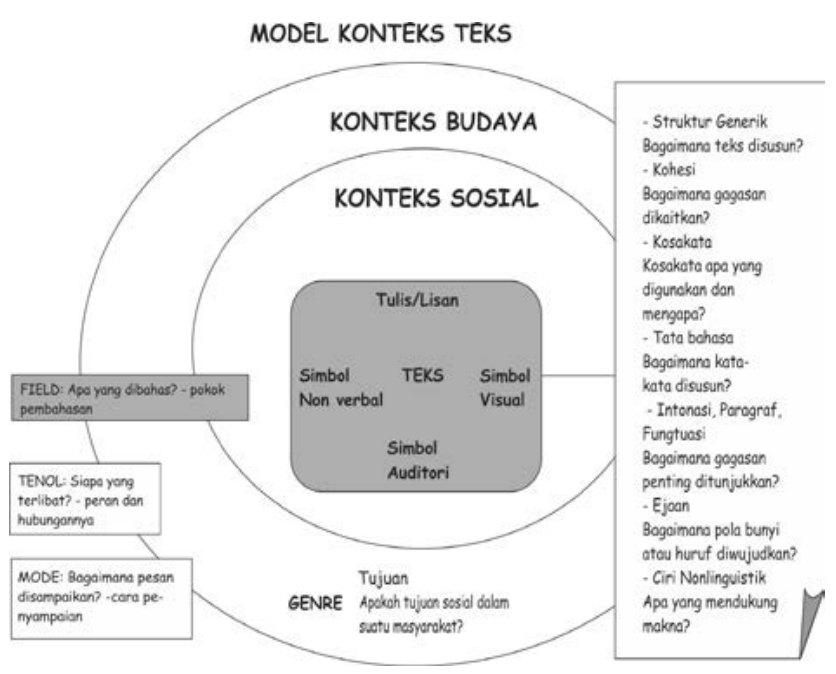

Bila kita mengenal genre teks, seperti: narasi, eksposisi, argumentasi, eksposisi, prosedur, negosiasi, prosedur kompleks, dan lain-lain, sesungguhnya hal itu merupakan bentuk teks yang sudah diarahkan untuk tujuan sosial tertentu.

Dalam Kurikulum 2013, lebih banyak lagi genre teks yang dibelajajarkan. Ada teks prosedur, prosedur kompleks, negosiasi, deskripsi faktual, laporan informasi, laporan prosedur, laporan fakta, penjelasan, diskusi, deskripsi sastrawi, pelaporan sastrawi, tanggapan, eksemplung, dll.

Pertanyaannya adalah mengapa pembelajaran teks tersebut harus diperbanyak? Jawabnya mungkin bisa kita kembalikan pada hasil-hasil riset Pembelajaran Berbasis Teks (Kurikulum, 2013) berikut. 
1. Hasil riset PISA (Program for International Student Assessment) untuk literasi bacaan, IPA, dan IPS menunjukkan bahwa, peringkat Indonesia baru bisa menduduki 10 besar terbawah dari 65 negara.

2. Hasil riset TIMSS (Trends in International Mathematics and Science Study) menunjukkan siswa Indonesia berada pada ranking amat rendah dalam kemampuan: a) memahami informasi yang kompleks, b) penguasaan teori, analisis, dan pemecahan masalah, c) pemakaian alat, prosedur dan pemecahan masalah, d) melakukan investigasi.

3. Hasil riset PIRLS (Program for International in Reading and Literacy Science) untuk membaca menunjukkan, siswa SD di Indonesia hanya mampu mencapai level menengah (intermediate), sementara lebih dari $50 \%$ siswa SD Taiwan mampu mencapai level tinggi (high) dan level mahir (advance) (Kemendikbud. 2013. Elemen Perubahan Kurikulum 2013).

\section{Pemilihan Materi/Aspek Kebahasaan}

\section{Acuan Pembelajaran Materi/Aspek Ke- bahasaan dan Keuntungannya}

Agaknya kita perlu mengacu pedomanpedoman berikut sebagai landasan mengapa pembelajaran bahasa Indonesia dilaksanakan demikian?

1. Materi yang diajarkan ditekankan pada kompetensi berbahasa sebagai alat komunikasi untuk menyampaikan gagasan dan pengetahuan.

2. Siswa dibiasakan membaca dan memahami makna teks serta meringkas dan menyajikan ulang dengan bahasa sendiri.

3. Siswa dibiasakan menyusun teks yang sistematis, logis, dan efektif melalui latihan-latihan penyusunan teks.

4. Siswa dikenalkan dengan aturan-aturan teks yang sesuai sehingga tidak rancu dalam proses penyusunan teks (sesuai dengan situasi dan kondisi: siapa, apa, di mana).

5. Siswa dibiasakan untuk dapat mengekspresikan dirinya dan pengetahuannya dengan bahasa yang meyakinkan secara spontan.

6. Konten ilmu pengetahuan diintegrasikan dan dijadikan penggerak konten pembelajaran lainnya (Kemendikbud. 2013. Standar Isi Kurikulum 2013)

Aspek kebahasaan diinklusikan dalam pembelajaran bahasa dengan atau melalui teks sebagai pintu masuk pembelajaran. Cara ini membawa banyak keuntungan atau manfaat, antara lain:

1.Bahasa dapat dipelajari seutuhnya (whole language).

2. Bahasa dapat dipelajari dalam koteks atau konteksnya.

3. Bahasa dapat dipelajari dalam pemakaian bahasa yang sesungguhnya.

4. Pembelajaran bahasa dapat bersifat pragmatis.

5. Pembelajaran keterampilan berbahasa relatif lengkap karena ada membaca (teks), mendengar/menyimak (rekaman cerita), menulis (peniruan model teks), presentasi hasil belajar (lisan).

6. Pembelajaran unsur bahasa termasuk ejaan lebih fungsional dan efektif karena pembelajarannya sesuai dengan yang muncul dalam teks yang sedang dipelajari pada pertemuan tersebut. Unsur bahasa dan ejaan yang lainnya dipelajari dalam pertemuan pembelajaran yang berikutnya (Kemendikbud. 2013. Standar Isi Kurikulum 2013)

\section{Pilihan Materi/Aspek Kebahasaan dalam Kurikulum 2018}

Mari kita perhatikan pilihan materi/ aspek kebahasaan yang ada pada Kurikulum 2013 pada setiap teks yang dibelajarkan sebagai pintu masuk pembelajaran bahasa Indonesia! Berikut contoh/sampelnya (Kemendikbud. 2013. Standar Isi Kurikulum 2013) 
Tabel 1: Pilihan Materi/Aspek Kebahasaan

\begin{tabular}{|c|l|l|}
\hline Kelas & \multicolumn{1}{|c|}{ Genre Teks } & \multicolumn{1}{c|}{ Materi/Aspek Kebahasaan } \\
\hline VII. & Deskripsi & kata umum, kata khusus, kata denotatif, kata konotatif, kata sifat \\
\hline & Narasi & kalimat langsung, kalimat tak langsung \\
\hline & Cerita Fantasi & ejaan dan tanda baca \\
\hline & Prosedur & $\begin{array}{l}\text { kalimat perintah, kalimat saran, kalimat majemuk, kata benda, kata } \\
\text { kerja, kalimat majemuk (dengan, hingga, sampai), konjungsi uru- } \\
\text { tan (kemudian, selanjutnya) }\end{array}$ \\
\hline & Puisi Rakyat & $\begin{array}{l}\text { (pantun, gurindam, syair) } \\
\text { ajakan, kalimat larangan dalam pantun. }\end{array}$ \\
\hline & Fabel/Legenda & - \\
\hline VIII. & Berita & bahasa baku dan tidak baku \\
\hline & Iklan, Slogan, Poster & - \\
\hline & Eksposisi & - \\
\hline & Puisi & ekspresi, lafal, tekanan, intonasi \\
\hline & Eksplanasi & - \\
\hline & Ulasan & - \\
\hline & Persuasi & konjungsi: supaya dan selagi \\
\hline & Drama & - \\
\hline IX. & Laporan Percobaan & $\begin{array}{l}\text { kalimat aktif, kata tugas, kosakata bidang limu pengetahuan, pe- } \\
\text { nulisan unsur serapan, }\end{array}$ \\
\hline & Pidato Persuasi & $\begin{array}{l}\text { kalimat aktif, kata tugas, kosakata emotif, kata bidang ilmu peng- } \\
\text { etahuan/istilah, sinonim, kata benda abstrak, perbendaharaan kata }\end{array}$ \\
\hline & Cerpen Narasi & kata/kalimat deskriptif, kata ekspresif, majas \\
\hline & Danggapan & kalimat aktif, kata tugas, bahasa deskriptif, bahasa penilaian \\
\hline & Narasi & $\begin{array}{l}\text { piranti kohesi dan koherensi, kata tugas, modalitas, kosakata emo- } \\
\text { tif dan evaluatif }\end{array}$ \\
\hline & kata/kalimat deskriptif, kata ekspresif, majas \\
\hline & & \\
\hline & &
\end{tabular}

\section{Pilihan Materi/Aspek Kebahasaan dalam} Kurikulum 2018

Mari kita perhatikan pilihan materi/ aspek kebahasaan yang ada pada Kurikulum 2013 pada setiap teks yang dibelajarkan sebagai pintu masuk pembelajaran bahasa Indonesia! Berikut contoh/sampelnya (Kemendikbud. 2013. Standar Isi Kurikulum 2013)

\section{Analisis Materi/Aspek Kebahasaan yang Dipilih}

1. Pada beberapa teks yang digunakan sebagai pintu masuk pembelajaran (yang integratif), terdapat aspek/materi kebahasaan yang tidak dicantumkan atau difokus untuk dibelajarkan. Hal ini akan menyulitkan guru dalam menyusun indikator capaian pada RPP. Hal ini tampak pada pembelajaran genre teks: Fabel/ Legenda, Iklan/ Slogan/ Poster, Eksposisi, Eksplanasi, Ulasan, dan Drama (Kemendikbud. 2013. Standar Isi Kurikulum 2013)

2. Teks-teks yang dikosongkan aspek kebahasaannya itu sesungguhnya dapat diisi atau dibelajarkan aspek kebahasaannya terkait dengan teks itu, seperti yang dijabarkan pada tabel 2 di halaman berikut. 
Tabel 2: Aspek Kebahasaan yang Bisa Diisi/Dibelajarkan

\begin{tabular}{|l|l|}
\hline \multicolumn{1}{|c|}{ Genre Teks } & \multicolumn{1}{c|}{ Aspek Kebahasaan yang Dapat Dibelajarkan } \\
\hline Fabel/Legenda & $\begin{array}{l}\text { - kata pembuka: kata sahibul hikayat, konon, syahdan, alkisah, } \\
\text { saur sepuh, tersebutkan cerita, antah barantah, tempo dulu, zaman } \\
\text { baheula, menurut yang punya cerita } \\
\text { - kata sambung atau kata tugas: maka, kemudian, selanjutnya }\end{array}$ \\
\hline -Iklan, Slogan, Poster & $\begin{array}{l}\text { - kalimat inti, kalimat turunan, frase pendek } \\
\text { - kosakata bombas, kosakata modal yang menantang }\end{array}$ \\
\hline Eksplanasi & - kalimat deklaratif, kalimat objektif \\
\hline Prosedur & $\begin{array}{l}\text { kalimat perintah, kalimat saran, kalimat majemuk, kata benda, kata } \\
\text { kerja, kalimat majemuk (dengan, hingga, sampai), konjungsi uru- } \\
\text { tan (kemudian, selanjutnya) }\end{array}$ \\
\hline Ulasan & $\begin{array}{l}\text { - kalimat tanggapan, kalimat imperatif, kata benda abstrak, kata } \\
\text { sifat }\end{array}$ \\
\hline Drama & $\begin{array}{l}\text { - tanda baca: titik dua, tanda kutip, tanda seru, tanda tanya (yang } \\
\text { diperlukan pada kalimat dialog) } \\
\text { - kalimat seru, kalimat tanya, kalimat direktif, kalimat dialogis/ } \\
\text { interaktif. }\end{array}$ \\
\hline
\end{tabular}

3. Ada pembelajaran genre teks yang perlu ditambahi aspek kebahasaannya (untuk dibelajarkan), misalnya:

Tabel 3:Aspek Kebahasaan yang Bisa Ditambahkan

\begin{tabular}{|l|l|}
\hline \multicolumn{1}{|c|}{ Genre Teks } & \multicolumn{1}{c|}{ Aspek Kebahasaan yang bisa ditambahkan } \\
\hline Narasi & $\begin{array}{l}\text { - kalimat subjektif (untuk narasi fiktif), kalimat objektif (untuk } \\
\text { narasi faktual) }\end{array}$ \\
\hline Puisi & $\begin{array}{l}\text { - gaya bahasa, majas, bahasa figuratif } \\
\text { - kalimat imajinatif }\end{array}$ \\
\hline Persuasi & - kalimat-kalimat imperatif \\
\hline Laporan Percobaan & - kalimat objektif \\
\hline
\end{tabular}

4. Ejaan seharusnya masuk pada semua pembelajaran bahasa Indonesia yang berbasis teks karena ejaan merupakan unsur mekanik yang diperlukan pada setiap pembelajaran, sesuai kasus ejaan yang muncul dalam teks tersebut. Yang dimaksud ejaan adalah Ejaan Bahasa Indonesia yang Disempurnakan (EYD). Ejaan ini mencakupi 4 bagian, yakni: 1) Pemakaian Huruf, 2) Penulisan Kata, 3) Penggunaan Tanda Baca, dan 4) Penyesuaian Penulisan Unsur Serapan.

\section{PENUTUP}

Kurikulum yang digunakan pada satuan Pendidikan Dasar dan Pendidikan Menengah adalah Kurikulum 2013. Kurikulum ini berbasis kompetensi. Artinya, jika kita ingin membelajarkan bidang studi tertentu kompetensi/kemampuan apa yang kita inginkan bisa dikuasai atau dicapai oleh peserta didik? Agar kompetensi-kompetensi yang diharapkan bisa dicapai, maka diperlukan perubahan-perubahan, seperti: perubahan isi, perubahan proses, dan perubahan evaluasi. Perubahan isi bersifat dua arah, yakni ke arah horizontal, dan ke arah vertikal.

Pembelajaran bahasa dilakukan secara holistik, komprehensif, integratif, dan komunikatif dengan menggunakan teks sebagai pengikatnya. Jadi teks adalah bangun kebahasaan yang berstruktur tertentu sesuai dengan genrenya. Sementara unsur kebahasaan adalah isi/pengisi bangun itu. Boleh dikatakan dalam sebuah analogi bahwa, bangun atau struktur 
teks adalah block of building-nya, dan unsur kebahasaannya adalah filler of block-nya.

Agaknya unsur kebahasaan yang dibelajarkan melalui teks atau wacana dalam Kurikulum 2018 untuk Pendidikan Dasar dan Menengah masih perlu dicermati, di-review, dan direvisi/disempurnakan.

\section{DAFTAR PUSTAKA}

Dirjen Pendidikan Dasar dan Menengah, Kemendikbud. 2017."SK No. 253/KEP.D/KR/ 2017" tentang Penetapan Satuan Pendidikan Pelaksana Kurikulum 2013.

Kemendikbud. 2013. "Permendikbud No. 160, Th. 2013" tentang Pemberlakuan Kurikulum 2013.

Kemendikbud. 2013. Pedoman Pelatihan Implementasi Kurikulum 2013. Jakarta: Kementerian Pendidikan dan Kebudayaan.

Kemendikbud. 2013. Elemen Perubahan Kurikulum 2013. Jakarta: Kementerian Pendidikan dan Kebudayaan.

Kemendikbud. 2013. Standar Kompetensi Kurikulum 2013. Jakarta: Kementerian Pendidikan dan Kebudayaan.

Kemendikbud. 2013. Standar Isi Kurikulum 2013. Jakarta: Kementerian Pendidikan dan Kebudayaan.

Kemendikbud. 2013. Standar Proses Kurikulum 2013. Jakarta: Kementerian Pendidikan dan Kebudayaan.

Kemendikbud. 2013. Standar Evaluasi Kurikulum 2013. Jakarta: Kementerian Pendidikan dan Kebudayaan.

Kemendikbud. 2013. Pembelajaran Berbasis Teks Kurikulum 2013. Jakarta: Kementerian Pendidikan dan Kebudayaan.

Kemendikbud. 2017. Model Pembelajaran Bahasa Indonesia Kurikulum 2013. Jakarta: Kementerian Pendidikan dan Kebudayaan.

Martha, I N. 2005. Penilaian Autentik dalam Proses Belajar-mengajar pada Jenjang Pendidikan Dasar dan Menengah. Singaraja: Universitas Pendidikan Ganesha.

Martha, I N. 2015. Model Konteks Teks. Singaraja: Universitas Pendidikan Ganesha.

Sandras JR, W.A. 1989. Just in Time: Making it Happen. New York.: Oliver Wight Limited Publication, Inc 